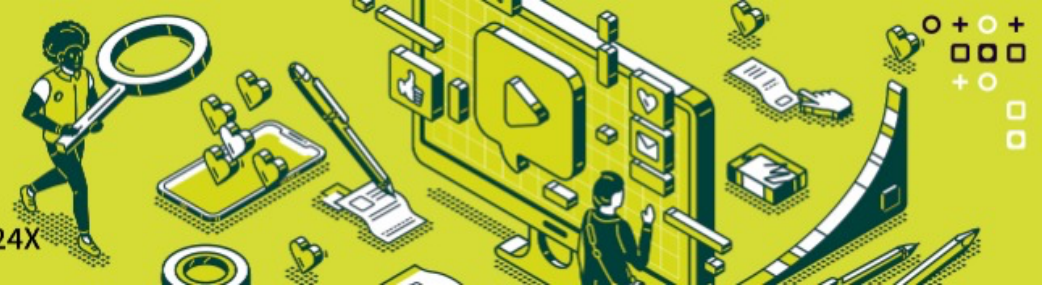

\title{
Design e Economia Criativa: Desenvolvimento de Aplicativo para difusão de PRODUÇÃO ARTÍSTICA AMAZONENSE
}

Design And Creative Economy: App Development for The Dissemination Of Amazon Artistic Production

${ }^{1}$ Patrícia dos A. Braga S. dos Santos; ${ }^{2}$ Marcicley Rego Raposo; ${ }^{3}$ Dayana Maria P. Teófilo; ${ }^{4}$ Luiz Guilherme O. Marques

\author{
${ }^{1}$ Universidade Federal do Amazonas - petbraga@ufam.edu.br \\ ${ }^{2}$ Universitat de Les Illes Balears - marcicley.reggo@gmail.com \\ ${ }^{3}$ Reggo Edições - dayana.teofilo@gmail.com \\ ${ }^{4}$ Universidade Federal do Amazonas - guilhermemarques@ufam.edu.br
}

\begin{abstract}
Resumo: Este artigo trata sobre o desenvolvimento de um aplicativo para dispositivos móveis voltado à difusão de conteúdo artístico regional. Para o desenvolvimento da proposta do aplicativo foi selecionado um artista local com base em sua produção, particularmente expoente no trânsito entre diversas formas de expressão artística: o poeta, compositor e músico amazonense Celdo Braga. A iniciativa nasceu da inquietação proveniente da observação de um mercado editorial impresso em retração, em especial no setor das artes e pouco acesso e interesse dos públicos mais jovens sobre a cultura artística local. Sendo assim, o projeto teve como objetivo geral desenvolver um aplicativo contendo a obra deste artista, a fim de estimular as novas gerações que se utilizam de tais mídias, a acessar conteúdo cultural e conhecer a rica produção deste autor. Com o intuito de fundamentar o desenvolvimento do projeto foi realizado um levantamento bibliográfico sobre conceitos relacionados ao Design editorial digital, interface digital, design de interação e usabilidade. A metodologia utilizada para chegar à solução de design foi o Design centrado no usuário (Human-Centered Design), com uma abordagem dividida em três etapas: descobrir, idealizar e prototipar. Em termos de conteúdo, foi inicialmente realizado um levantamento do acervo do autor Celdo Braga, seguido por entrevistas e áudios inseridos no aplicativo. A partir da seleção do material pertinente, foi construído então o conceito e o protótipo funcional do aplicativo que apresenta várias obras como músicas, poesias e sons captados ou inspirados na natureza, dispostas em modo digital, com elementos multimídia e interativos.
\end{abstract}

Palavras-chave: Design, economia criativa, cultura regional, aplicativos digitais.

\begin{abstract}
This paper presents the development of an application for mobile devices aimed at disseminating regional artistic content. For the development of the application proposal, a local artist was selected based on his production, particularly exponent in the transit between different forms of artistic expression: the Amazonian poet, composer, and musician Celdo Braga. The initiative was born from the restlessness arising from the observation of a shrinking print publishing market, especially in the arts sector and little access and interest from younger audiences about the local artistic culture. Thus, the project had as general objective to develop an application containing the work of this artist, in order to encourage the new generations who use such media, to access cultural content and learn about the rich production of this author. In order to support the development of the project, a bibliographic survey was carried out on concepts related to digital editorial design, digital interface, interaction design and usability. The methodology used to reach the design solution was User-Centered Design (Human-Centered Design), with an approach divided into three stages: discover, idealize, and prototype. In terms of content, a survey of the author Celdo Braga's collection was initially carried out, followed by interviews and audios included in the application. From the selection of relevant material, the concept and functional prototype of the application was built, which presents several works such as music, poetry and sounds captured or inspired by nature, arranged in digital mode, with multimedia and interactive elements.
\end{abstract}

Keywords: Design, creative economy, regional culture, digital applications. 


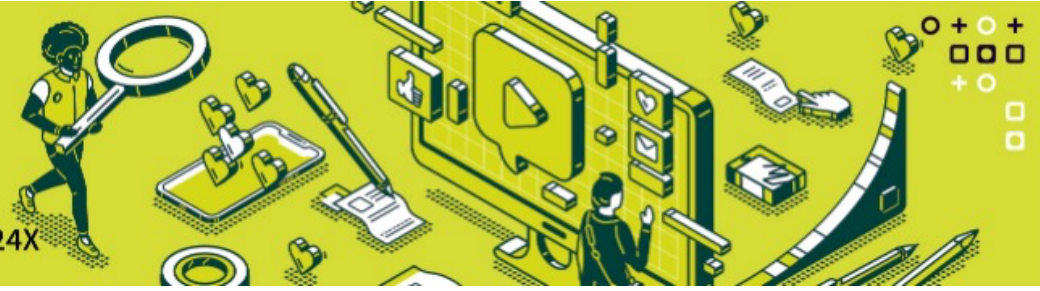

\section{INTRODUÇÃO}

A difusão de conteúdos culturais, em especial de poesias e textos, sempre enfrentou dificuldades no Brasil e no estado do Amazonas esta realidade não é diferente. Embora o número de editoras tenha crescido na última década, a publicação, venda e retorno financeiro, especialmente de produtos de conteúdo regional, ainda enfrentam vários obstáculos. Conforme levantamento realizado pela Nielsen Book e coordenado pela Câmara Brasileira do Livro (CBL) e pelo Sindicato Nacional dos Editores de Livro (SNEL) nos últimos 14 anos, o faturamento do setor editorial caiu $20 \%$ e apresentou queda de $6 \%$ nas vendas realizadas ao mercado, no ano base de 2020 , o que significa um recuo de $10 \%$, considerada a variação do IPCA no período.

Uma das principais razões para esta queda gira em torno, especialmente, do elevado custo de produção das publicações impressas, além dos custos de distribuição e vendas, custos estes, que em uma região como a do estado do Amazonas, tornam-se ainda mais onerosos em função das grandes distâncias entre os municípios e dificuldades de locomoção, uma vez que existem poucas estradas e a maior parte dos percursos são fluviais. Em contraponto aos números desanimadores do mercado editorial tradicional (impresso) observa-se um crescimento considerável dos e-books e aplicativos para dispositivos móveis com conteúdo cultural. Segundo a pesquisa Produção e Venda do Mercado Editorial (2019), também realizada pela Nielsen Books, coordenada pela CBL/SNEL, no ano de 2019 ocorreu um aumento significativo na participação de alguns canais de distribuição e comercialização na área editorial, como livrarias exclusivamente virtuais e internet/market places que tiveram um participação de $12,7 \%$ de participação no faturamento do setor em comparação do ano anterior, representando um aumento de $84 \%$. Um fator que impulsiona este cenário é a crescente popularização dos tablets e smartphones. De uma forma geral o mercado editorial está adaptandose a este novo horizonte a exemplo do que ocorreu com o mercado fonográfico. No estado do Amazonas ainda são escassas as experiências com o desenvolvimento de aplicativos que disponibilizem cultura regional, como é possível verificar em lojas virtuais como Apple Store e Play Store.

A distribuição de obras de autores regionais através de recursos digitais representa uma oportunidade de contornar os entraves, impulsionando a economia criativa no estado do Amazonas, uma vez que envolve a participação de diversos atores desta indústria como poetas, músicos, designers de interface digital, programadores, entre outros. A dinâmica estabelecida através de projetos desta natureza pode contribuir para a economia da região, gerar renda em diversos setores e também proporcionar retorno financeiro aos artistas de diversas formas como comercialização de direitos ou cotas de patrocínio presentes nos aplicativos, algo positivo se considerarmos que a maioria do artista não consegue obter seu sustento apenas através de sua arte. Sendo assim, diante do problema que têm se estabelecido na região com as dificuldades encontradas no mercado editorial tradicional, acredita-se que o aprofundamento nas pesquisas sobre o público consumidor de conteúdos digitais no amazonas e o desenvolvimento concreto de produtos desta natureza, aliados ao poder de difusão e alcance das mídias digitais, podem representar uma alternativa viável de sustentação dos artistas.

Diante deste cenário, o projeto teve como objetivo o desenvolvimento de um aplicativo para dispositivos móveis voltado à difusão de conteúdo artístico regional, gerado a partir de uma pesquisa originalmente desenvolvida no ano de 2015 com apoio financeiro do Conselho Nacional de Desenvolvimento Científico Tecnológico (CNPq) e Ministério da Cultura (MinC) por meio de chamada voltada à Economia Criativa e revisado e atualizado em 2021 com o intuito de relançamento do aplicativo. Para o desenvolvimento da proposta do aplicativo foi selecionado um artista local com base em sua produção, particularmente expoente 


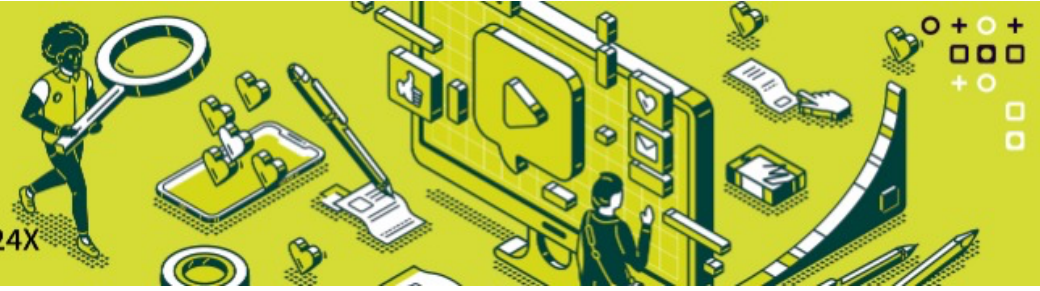

no sentido do trânsito entre diversas formas de expressão artística: o poeta, compositor e músico amazonense Celdo Braga.

Celdo Braga, é amazonense de Benjamin Constant, nascido 1952. É formado em letras pela PUC-RS, membro da União Brasileira de Escritores e possui consolidada produção literárias, entre as quais destacam-se: Cordel Verde, Entranhas do Mato, O Eco das Águas, Água e Farinha. Celso Braga, além de poeta é também músico e possui particular interesse por sons experimentais que invocam os sons da floresta amazônica. A trajetória musical de Celdo Braga é marcada e, mais comumente conhecida, pelo trabalho que desenvolveu junto ao grupo Raízes Caboclas, projeto artístico-musical centrado na temática amazônica que, ao longo de 20 anos, e que o consagrou no cenário regional, nacional e internacional. Posteriormente, passou a integrar o grupo musical Imbaúba.

\section{REVISÃo BIBLIOGRÁFICA}

Com o intuito de melhor compreender aspectos pertinentes relacionados ao tema, um levantamento bibliográfico sobre conceitos relacionados aos temas de Design editorial digital, interface digital, design de interação e usabilidade.

\subsection{Design editorial digital e design de ApPS}

O Design Editorial abrange o projeto gráfico desenvolvido para produção tanto impressa quanto digital de revistas, jornais, livros e conteúdos diversos e envolve o trabalho de diagramação e disposição de elementos a fim de tornar a leitura mais ágil e agradável. Um livro eletrônico é a versão digital de um livro impresso em papel. Pode ser lido em equipamentos eletrônicos como computadores, notebooks, tablets, eReaders ou mesmo em smartphones que suportem este recurso, caracterizando sua portabilidade. Possuem fácil manipulação, sendo possível, por exemplo, a ampliação do tamanho de letra e da utilização dos recursos de pesquisa de palavras. Atualmente, o mercado editorial está voltado para os tablets, dispositivos móveis que possuem diversas funções de um computador pessoal e que permitem a leitura de livros, revistas e jornais. O iPad, da Apple, permite a leitura de conteúdo editorial por meio da tecnologia touchscreen, onde o usuário pode manipular o conteúdo com o toque dos próprios dedos diretamente na tela.

As publicações editoriais, portanto, se adaptaram a essa tecnologia. Muitas revistas digitais apostam na interatividade, possibilitando ao usuário assistir vídeos, manipular imagens, entre outros recursos em suas próprias páginas. Além dos ebooks e aplicativos de leitura consolidados ou genéricos, também tem sido uma crescente o desenvolvimento de aplicativos com objetivo de difusão de conhecimentos gerais ou específicos, aprendizado de idiomas e sobre conteúdos artísticos. Os aplicativos têm sido bastante utilizados também por museus e galerias de arte. São exemplos deste tipo de aplicativo o Google Arts \& Culture, History of Art, Museu do Amanhã e Louvre. Segundo SCHERRER (2018) os aplicativos trouxeram uma transformação no panorama de acesso a informações, bens e serviços, uma vez que, desde que haja condições estruturais de acesso à internet ou à rede móveis das operadoras telefônicas, se beneficiam da mobilidade dos smartphones e ampliam os campos de possibilidades dos usuários.

\subsection{A INTERFACE DIGITAL}

A ideia de interface indica essencialmente a comunicação entre no mínimo dois sistemas, diferentes ou que possuem de alguma maneira incompatibilidades funcionais. A interface gera uma possibilidade de adaptação entre os sistemas e gera uma interconexão (Coelho, 2008). Segundo Radfahrer (2000, p.92) interface "é o 


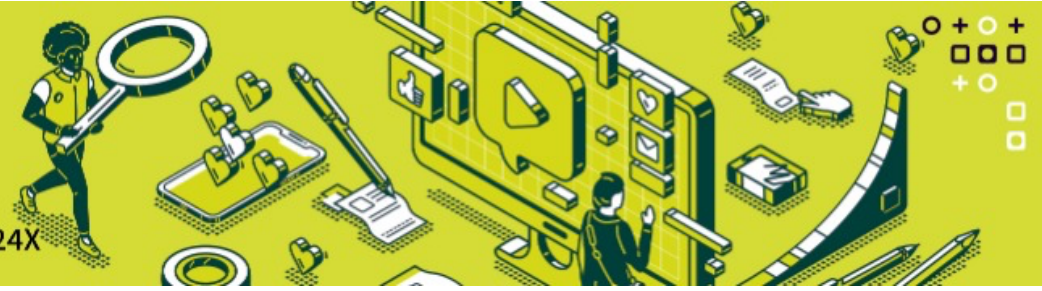

ambiente gráfico do produto digital, o canal de comunicação do usuário final com o conteúdo de um sistema de computador. Entre outras palavras, é onde tudo acontece".

Uma boa interface oferece uma real possibilidade para atender as necessidades de um usuário fazendo com que este se concentre melhor na tarefa que está realizando, permitindo que ele encontre de forma fácil e rápida a sua solução. Para que isso ocorra da melhor maneira possível, é necessário utilizar o Design como uma ferramenta essencial para este tipo de projeto, uma vez que, com os conhecimentos da linguagem visual a interação usuário-máquina terá um fluxo mais harmonioso. Em um sistema onde a atuação humana acontecerá, o uso do design se faz por meio da ergonomia.

De acordo com Moraes e Santa Rosa (2008) o objetivo do design em uma interface é priorizar os objetivos do produto e as necessidades do usuário. $O$ designer deve desenvolver seu projeto utilizando-se de técnicas de projeto e avaliação de usabilidade para que a interação do usuário se torne o mais simples e eficiente possível. Existem aqueles, é claro, que voltam seu foco apenas para as questões de usabilidade fazendo com que a estética seja deixada de lado, o que pode comprometer o sucesso de um projeto. Ainda segundo os autores, o desenvolvimento de interfaces "apresenta-se como um campo novo e promissor de trabalho para designers. Sua implementação originou a Ergonomia de Software ou Ergonomia de Programas".

Ao se projetar para meios digitais, Braga (2004) afirma que existem mais fatores envolvidos além do uso, por parte do receptor da mensagem. O usuário não apenas observa e lê, ele também decide e clica, e a interface é um meio que envolve uma curva de aprendizagem do usuário, que pode mudar toda a metodologia de uso.

\subsection{O DESIGN DE INTERAÇÃO}

O Design de Interação é uma maneira de "criar experiências que melhorem e estendam a maneira como as pessoas trabalham, se comunicam e interagem". (PREECE et al, 2002) Trata-se também do Design voltado às experiências dos usuários, esclarece o relacionamento entre as pessoas e os meios interativos que elas utilizam. Esta área do conhecimento pode ser utilizada para o desenvolvimento de interfaces centradas ao usuário. Sendo importante para definir as reais necessidades de quem utilizará o produto final, facilitando o processo de familiarização com a interface. A prática do Design de Interação é baseada na compreensão dos usuários reais, seus objetivos, tarefas, experiências, necessidades e desejos.

\subsection{A USABILIDADE}

Inicialmente o termo usabilidade pode significar coisas diferentes para certos indivíduos, alguns designers definem o vocábulo como "uso amigável", outros consideram como "Design centrado no usuário". Coelho (2008) afirma que: "o termo usabilidade assume significados específicos para cada pessoa envolvida na avaliação de interfaces para descrever o que quer que seja que eles estejam realizando". A usabilidade é um atributo qualitativo, afirma Nielsen (2003), ou seja, não interessa o número de funcionalidades que ele tem a oferecer, mas quanto ele é determinante na facilidade de uso para o usuário.

Para a projetação de interfaces usáveis, Nilsen (1993) define cinco atributos globais de qualidade, a saber:

- Facilidade de aprendizado: O sistema deve permitir que o usuário consiga rapidamente explorá-lo e realizar suas tarefas com ele.

- Eficiência de uso: o sistema deve permitir que o usuário, tendo aprendido a interagir com ele, atinja altos níveis de produtividade em suas tarefas. 


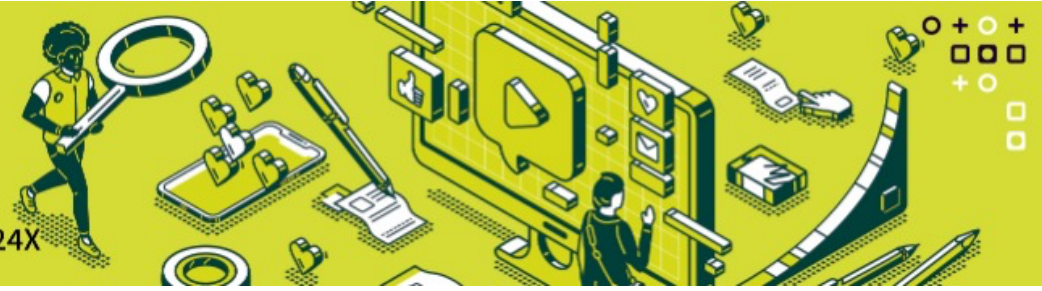

- Facilidade de memorização: o sistema deve permitir que o usuário não frequente seja capaz de realizar suas tarefas sem precisar reaprender como utilizá-lo.

- Baixa taxa de erros: o sistema deve permitir que o usuário realize suas tarefas sem transtornos, recuperando de erros, caso ocorram.

- Satisfação subjetiva: o sistema deve fazer com que o usuário o considere agradável e se sinta subjetivamente satisfeito com ele.

Krug (2014) descreve vários princípios à utilização da web por parte do usuário, refletindo sobre o seu pensamento modo de agir ao buscar informações. Entre estes princípios, destacam-se:

- Ir Direto ao ponto: os usuários não gastam tempo para descobrir como as coisas funcionam, mas uma vez encontrando determinado modo que funciona, sempre recorrem a ele, mesmo que não seja o mais fácil;

- Hierarquia visual clara: a clareza na hierarquia visual das informações e dos grupos de informações evita que o usuário tenha dúvidas ou suposições erradas sobre o que está exposto. Quanto mais importante, mais proeminente deve ser a informação; as características e a relação visual das informações expressam a relação lógica entre os itens; agrupamentos visuais ajudam o usuário a compreender corretamente as informações da página;

- Dividir as páginas em áreas claramente definidas: isto ajuda o usuário a compreender as sessões da página e o que pode fazer com cada uma delas de maneira rápida, possibilitando que ele direcione o seu foco para as partes mais importantes e ignore outras partes menos importantes de maneira segura;

- Deixar óbvio o que deve ser clicado: considerando uma sequência de passos em uma navegação, é importante deixar explícito qual pode ser o próximo passo, deixando aparente o que é um item clicável e o que não é, por meio do formato (botões, guitas, etc.), da localização (em barras de menu por exemplo) e formatação (cor, sublinhado);

- Minimizar a confusão visual: consiste no cuidado de não aglomerar ênfases visuais ou informações que compitam entre si em um mesmo espaço e colocá-las em uma estrutura organizada, como um grid;

Desta forma, com base na literatura consultada, observa-se que a o desenvolvimento do aplicativo deve ser pautado em fundamentos teóricos que circulam em torno principalmente da facilidade de uso e experiência satisfatória do usuário, um item fundamental para a aceitação do produto no mercado.

\section{MATERIAIS E MÉTOdOS}

\subsection{Metodologia Projetual}

A Metodologia de Design pode ser entendida como um processo esquematizado e apoiado em etapas distintas, com o objetivo de aperfeiçoar e auxiliar o Designer (ou a equipe de Design) no desenvolvimento ou concepção de soluções para um determinado problema, oferecendo um suporte de métodos, técnicas ou ferramentas. A metodologia utilizada para chegar à solução de design será a Human-Centered Design (Design centrado no usuário), termo que ganhou notoriedade na década de 80 através do livro de Donald Norman "User-Centered System Design: New Perspectives on Human-Computer Interaction" e consolidado posteriormente em "O Design do dia-a-dia", livro do mesmo autor (2006). A abordagem adotada no presente 


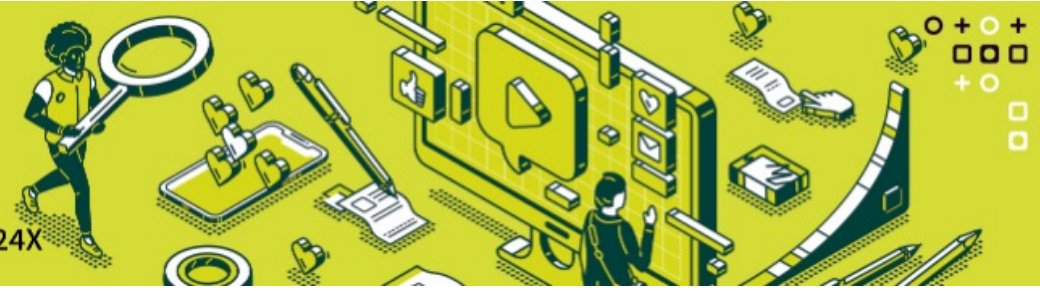

estudo é dividida em três etapas, a saber: descobrir (discover), idealizar (ideate) e prototipar (prototype). Segundo a +Acumen (2013) o processo de design centrado no usuário oscila entre pensamentos muito tangíveis e muito abstratos durante as três fases:

- Descobrir (discover): trata-se de ir aonde está o usuário e aprender com seu comportamento, seus costumes e sua cultura. É importante, também consultar a opinião de especialistas que podem oferecer um profundo conhecimento sobre o assunto (neste caso, o referencial teórico faz as vezes do especialista).Esta primeira fase pode ser resumida como uma imersão no contexto em que o usuário está inserido para que se possa, então, a partir de seu ponto de vista, entender suas reais necessidades.

- Idealizar (ideate): irá buscar soluções a partir dos conhecimentos obtidos em campo. A partir de técnicas como brainstorms são geradas alternativas que podem solucionar determinado problema.

- Prototipar (prototype): consiste em construir sistemas representativos das soluções propostas, com o intuito de validar ou refutar tais ideias a partir dos feedbacks que são dados pelos usuários.

A estruturação inicial do aplicativo foi realizada através do o desenvolvimento de framework. Segundo Cooper (2005), do framework define a estrutura geral da experiência dos usuários, desde o arranjo dos elementos funcionais na tela, comportamentos interativos e princípios de organização subjacentes, linguagem visual para expressar dados, conceitos, funcionalidades, e identidade da marca. $O$ autor identifica os três tipos de framework, a saber: de interação, visual e industrial, este último diz respeito à relação entre um produto físico e sua interface (hardware x software) e não será considerado, pois o produto que será desenvolvido trata-se de uma aplicação para plataformas móveis.

Após definir o fluxo das informações, a aparência geral das alternativas e selecionar a que melhor atende aos requisitos projetuais, foi desenvolvido um protótipo de baixa-fidelidade em papel testar a usabilidade da interface escolhida. Preece (2005), afirma que os protótipos de baixa-fidelidade são úteis porque tendem a ser simples, baratos e de rápida produção. Isso também significa que podem ser rapidamente modificados, oferecendo, portanto, suporte à exploração de designs e ideias alternativas.

\subsection{MATERIAIS}

Para a produção do protótipo foi necessária a utilização de equipamentos como o Computador desktop com capacidade para edição de vídeos, Software de tratamento de imagens, Notebook, Câmera fotográfica digital e Filmadora Digital. Os equipamentos utilizados foram disponibilizados pela Universidade proponente da pesquisa e pelos membros da equipe executora.

O Aplicativo, originalmente desenvolvido no ano de 2015 teve seu protótipo funcional desenvolvido através do Software Adobe in Design e visualizado através do Adobe Viewer. Em 2020, diante da realidade da pandemia e necessidade de levar a cultura por meios remotos, a iniciativa foi retomada, sendo necessária a atualização da tecnologia de desenvolvimento do protótipo, até mesmo, em função da descontinuidade de alguns dos serviços em que foi desenvolvido. $O$ aplicativo foi revisado e está em fase de reconstrução de sua interface por meio de softwares de desenvolvimento de aplicativos mais atuais, mais especificamente o Adobe XD. 


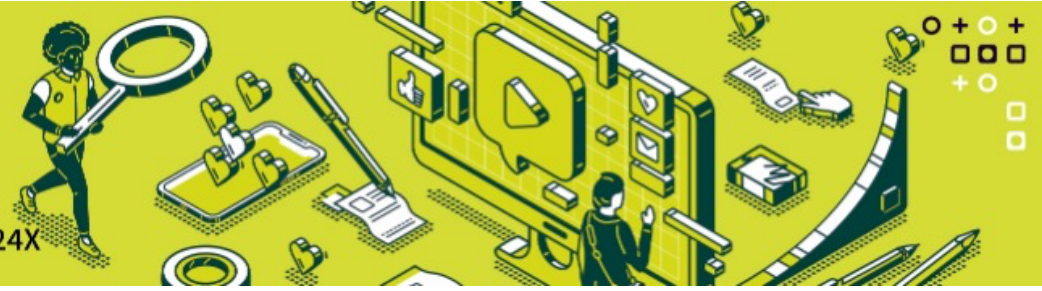

\section{Resultados}

$\mathrm{Na}$ fase inicial do projeto a equipe concentrou-se no levantamento de dados necessários para fundamentar o desenvolvimento do aplicativo, tais como aprofundamento do referencial teórico e, especialmente, pesquisa sobre o autor e reunião de seu acervo musical e literário, com o intuito de digitalizar e ordenar a sua produção. Este levantamento foi realizado através de consultas bibliográficas e a sites especializados em cultura regional. A partir disto, foi também realizada uma entrevista com o artista, durante a qual foram esclarecidas dúvidas sobre sua obra e coletadas informações mais consistentes sobre sua trajetória profissional. Durante esta fase percebeu-se que a obra do autor era muito extensa e não seria possível contemplá-la em sua totalidade no aplicativo, por isso, juntamente com o autor, a equipe realizou uma seleção de obras que contemplassem as suas características mais significativas e que melhor se adequassem à mídia digital.

Esta seleção também levou em consideração questões de direitos autorais, pois, especialmente em sua trajetória musical, o artista e compositor participou, até determinado momento de sua carreira, de um grupo de renome no Amazonas composto por diversos integrantes que até hoje seguem carreira e detêm direitos às composições. Por esta razão, no campo musical, foram selecionadas músicas e sons cujo artista detinha os direitos ou que foram realizadas em conjunto com seu novo grupo, o "Embaúba".

A partir desta seleção foi possível, então, definir a quantidade de texto, imagens e sons que iriam compor o aplicativo, possibilitando que a equipe passasse ao planejamento do fluxo de informações e design da interface. Conforme descrito anteriormente, a metodologia adotada para orientar o desenvolvimento da solução de design e funcionamento do aplicativo em questão foi a HCD - Human-Centered Design (Design centrado no usuário), com abordagem focada nas etapas básicas: descobrir (discover), idealizar (ideate) e prototipar (prototype).

1) Fase 01 Descobrir: Durante esta fase a equipe dedicou-se a conhecer o universo do artista, para, então, passar a conhecer a característica de seu público. Além de levantamento bibliográfico, foi realizada entrevista com o artista, durante a qual também foram gravados vídeos e áudios para o aplicativo.

2) Fase 02 Idealizar: foram realizadas diversas sessões de brainstorming com a equipe, a partir das quais foram geradas diversas alternativas e então definidas soluções para as seguintes questões:

- Nome do aplicativo: Foi escolhida a denominação de Sarau na Floresta em alusão à sua oba que reúne sons naturais, textos poéticos e composições.

- Fluxo de informações: Esquema de funcionamento do aplicativo, conforme detalhado posteriormente;

- Características visuais do layout: Foram definidas como cores a serem utilizadas: Tons de verde, areia e terra a fim de caracterizar o contexto regional de sua obra;
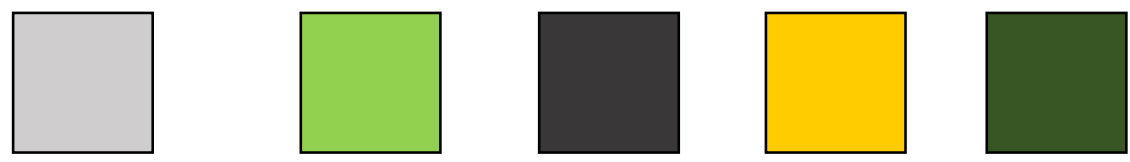

Estilo de Texto: Fonte sem serifa para textos corridos e títulos das partes textuais e com serifa discreta na marca e tela de apresentação; 
AEC\&D ARTE.EDUCAÇÃO.COMUNICAÇÃO.DESIGN

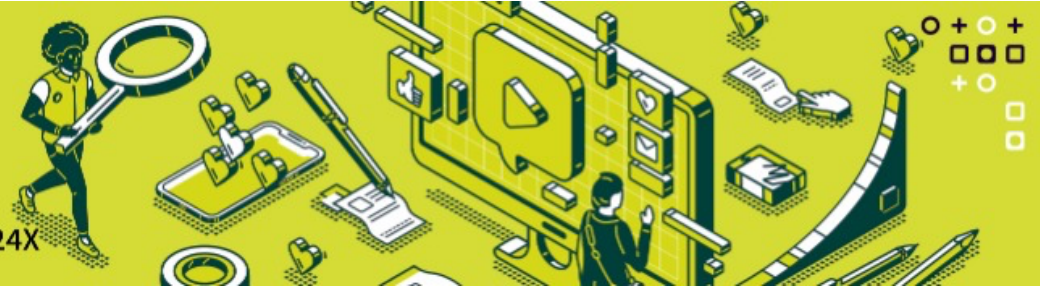

3) Fase 03- Prototipar: foi dado início à construção do protótipo do aplicativo propriamente dito, iniciando pela inserção da grade para orientação de layout, seguida pela inserção de texto e imagens, finalizando com os botões e atalhos funcionais.

O aplicativo inicia com uma animação opcional, ou seja, que pode ser interrompida pelo usuário a qualquer momento através de toque na tela, com fundo musical do autor remetendo a sons da floresta e transição entre imagens estilo "Fade". O Fundo musical também pode ser desligado ou interrompido.

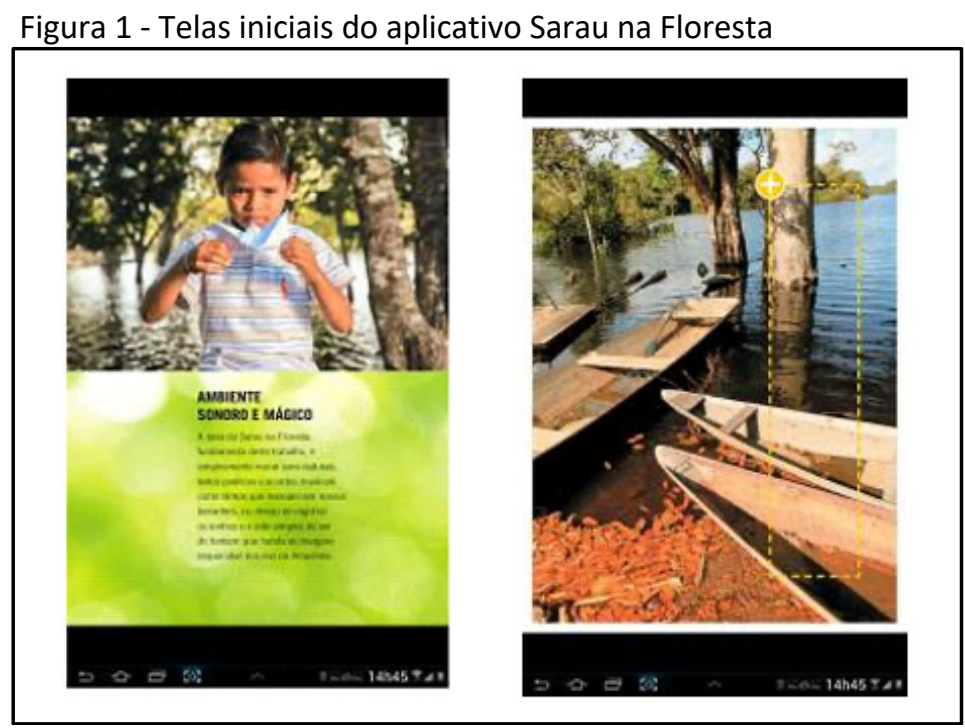

Fonte: Os autores (2021)

O conteúdo está categorizado em duas áreas principais sobre música e poesia, nas quais se encontram as obras selecionadas. Usuário muda de página através de deslize na tela.

Figura 2 - Telas de seleção de conteúdo

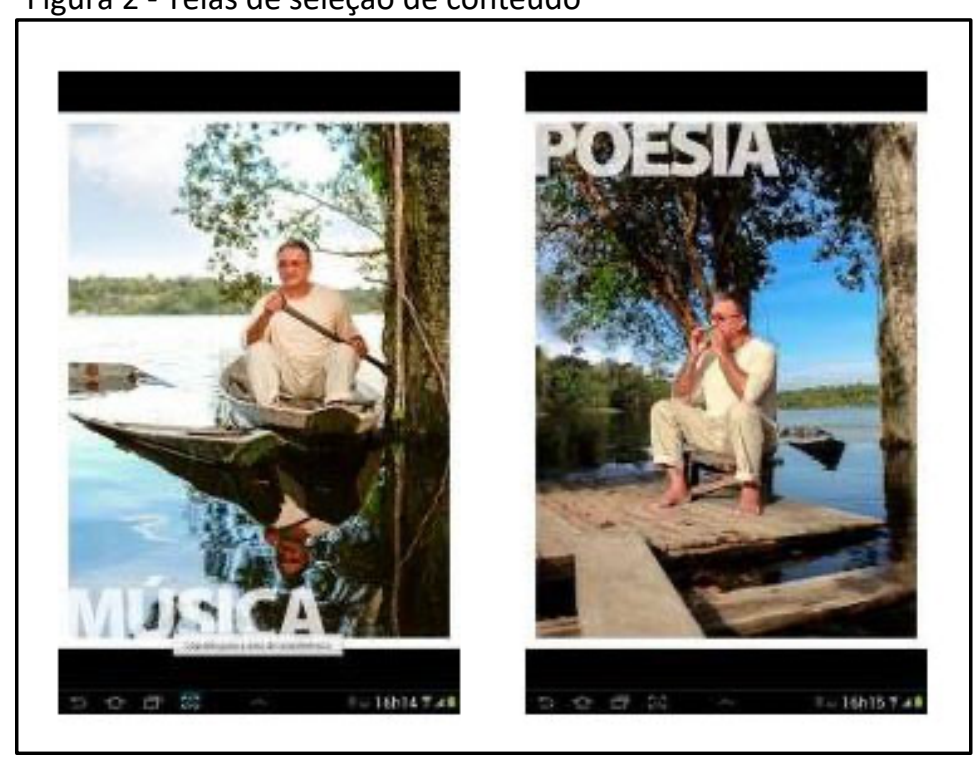

Fonte: Os autores (2021)

Ao deslizar a tela o usuário tem acesso a um texto sobre poesia, seguido por biografia resumida do artista, ambos acionados através de toque no ícone em forma de cruz pelo usuário. Caso siga para a opção "música" as telas seguintes tratam sobre a trajetória Musical do artista, acionadas através de toque no ícone em forma 


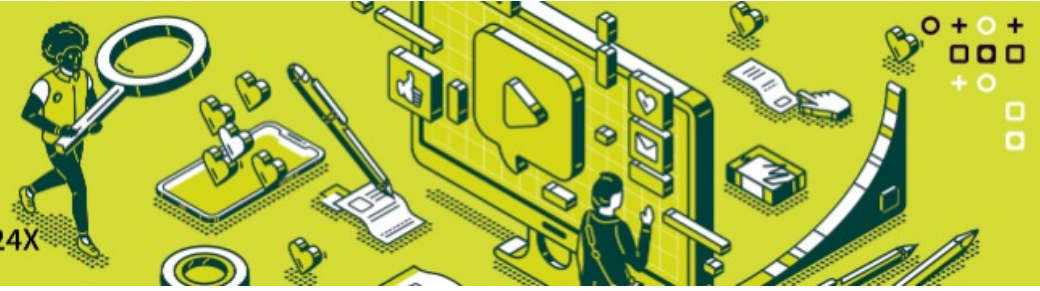

de cruz, seguido por músicas do artista disponibilizadas para ouvir que podem ser selecionadas através de toque na tela.

Figura 3 - Telas de introdução dos conteúdos sobre poesia e música

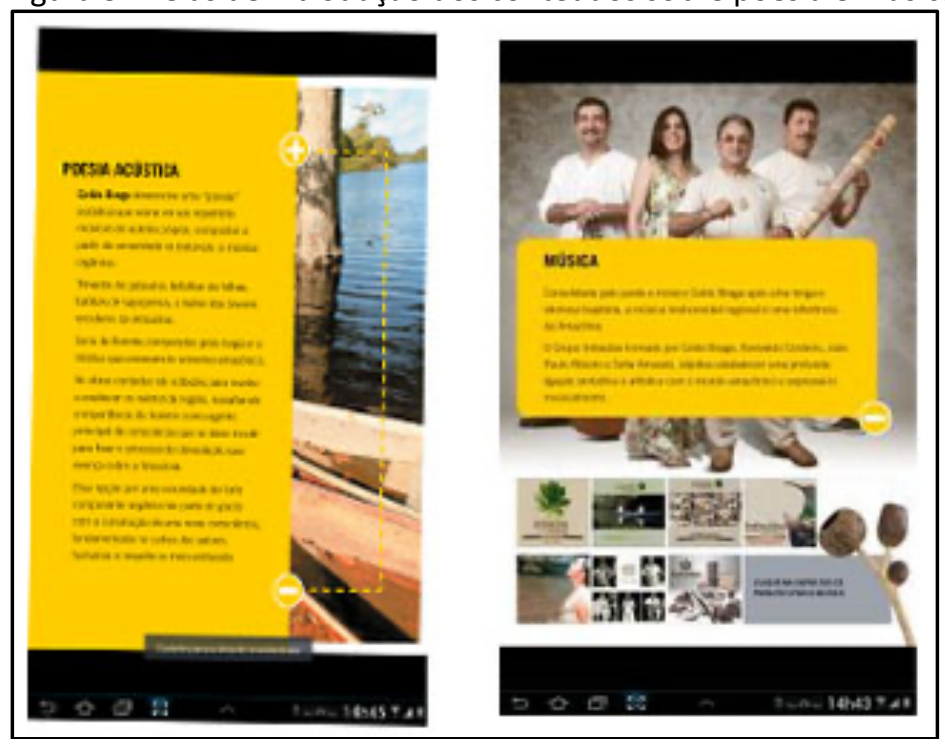

Fonte: Os autores (2021).

Cada um dos setores apresenta conteúdos multimídia de apoio, por exemplo, na parte sobre poesia, além de dos textos, é possível assistir a vídeos com o artista recitando sua obra. No setor sobre música, estão disponíveis áudios e vídeos, além de comentários do artista. Todo o conteúdo selecionado e a linguagem visual aplicada no layout do aplicativo buscou proporcionar harmonia com o perfil e principais conceitos priorizados pelo artista, tais como a comunhão com a natureza e valorização da cultura e do ser amazônico.

\section{CONSIDERAÇÕES FINAIS E RECOMENDAÇÕES}

Ao observar o produto resultante do projeto considera-se que o objetivo do estudo foi alcançado com êxito, uma vez que foi possível chegar à construção do protótipo funcional do aplicativo "Sarau na Floresta" conforme a proposta inicial.

Para os bolsistas e coordenação, o projeto representou um aprendizado valioso sobre a produção de aplicativos digitais, pois envolveu a necessidade de aprofundamento sobre conhecimentos de diversas naturezas tais como: captação e edição de imagens, captação e edição de sons, adequação de formatos e tamanhos de arquivos e comportamento de conceitos de design em interfaces digitais.

A maior contribuição do projeto reside na possibilidade de disponibilização de conteúdo cultural à uma enorme faixa de público, que não seria atingida através dos meios tradicionais de difusão, além de melhorar a experiência sensorial através de associação de sons e outras ferramentas à forma de dispor a poesia do autor, proporcionando ao usuário algo diferenciado, agregando valor e sendo mais atrativo, em especial ao público jovem.

Além da atualização de conteúdo e tecnologia já realizados, recomenda-se que o protótipo atual seja submetido a testes de usabilidade a fim de identificar possíveis potenciais de otimização. Recomenda-se também a participação profissionais de TI/programadores para a construção na versão final do aplicativo antes de sua disponibilização ao público, além de posterior expansão do número de artistas contemplados. 


\section{REFERENCIAS}

+ACUMEN. An introduction to Human-Centered Design: The Design Process. 2013. IDEO. 2013.

readings.pdf>BRAGA, Alexandre Santaella. Design de Interface: As origens do design e sua influência na produção da hipermídia. 2004. Dissertação (Mestrado em Comunicação e Semiótica) - Programa de Mestrado em Comunicação, PUC-SP, São Paulo.

CBL/SNEL/ Nielsen. PRODUÇÃO E VENDAS DO SETOR EDITORIAL ANO BASE BRASILEIRO. Ano Base 2019. Maio de 2020. Disponível em: https://snel.org.br/pesquisas/. Acesso em 02/08/2021.

CBL/SNEL/ Nielsen. PRODUÇÃO E VENDAS DO SETOR EDITORIAL ANO BASE BRASILEIRO. Ano Base 2020. Maio de 2020. Disponível em: https://snel.org.br/pesquisas/. Acesso em 02/08/2021.

COELHO, Luiz Antonio L. Conceitos-chave em design. Rio de Janeiro: Novas Ideias, 2008.

COOPER, W.W., L. Seiford and J. Zhu. Handbook of DEA. Kluwer Academic Publishers. 2004.

KRUG, Steve. Não me faça pensar: atualizado. Rio de Janeiro: Alta Books, 2014.

MORAES, Ana Maria de; SANTA ROSA, José Guilherme. Avaliação e projeto no design de interfaces. Rio de Janeiro: 2AB, 2008.

NIELSEN, Jakob. Usabilty Engineering, Morgan Kaufmann, Inc. San Francisco, 1993.

NORMAN, D. A., and Draper S. W.. User Centered System Design: New Perspectives New perspectives on Human-computer Interaction. CRC Press, 1986.

NORMAN, Donald A. O Design do dia-a-dia. Rio de Janeiro: Ed. ROCCO, 2006.

PREECE, Jennifer; Rogers, Yvone; Sharp, Helen. Interaction design: beyond human computer interaction. John Wiley \& Sons, New York, 2002.

RADFAHRER, Luli. Design/web/design. São Paulo: Market Press, 2000.

SCHERRER, Rodrigo. Consumo de Aplicativos para Smartphones: uma discussão sobre a constituição identitária e seus campos de possibilidades. Congresso Nacional de Comunicação e Consumo (COMUNICON). 2018. 